\title{
Political Attitudes and Political Participation: A Panel Study on Socialization and Self-Selection Effects among Late Adolescents
}

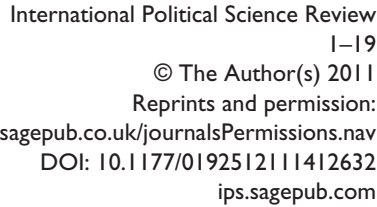

(\$SAGE

\section{Ellen Quintelier and Marc Hooghe}

\begin{abstract}
The expectation that participation entails socialization effects on political attitudes is not routinely tested in a longitudinal manner. In this article, we report on a two-year panel study among 4325 late adolescents in Belgium. By means of a cross-lagged structural equation model, it was ascertained that the relationship between participation and attitudes is reciprocal. The relationship between participation (at Timel) and attitudes (at Time2) was significantly stronger than the relationship between attitudes (at Timel) and participation (at Time2). Therefore, the current study supports the socialization perspective. Individual and collective forms of participation have equally strong socialization effects.
\end{abstract}

\section{Keywords}

political participation, political socialization, panel study, Belgium, dissonance theory, structural equation modeling

\section{Introduction}

It is a well-established fact that participants in political action tend to be more knowledgeable about politics and are more strongly interested in political matters. On average, they also have higher levels of political efficacy, and for most forms of political participation it has been documented that participants have higher political trust levels than non-participating citizens (Almond and Verba, 1963: 90; van Deth et al., 2007). Determining the causal relationship between both phenomena, however, has been the topic of an ongoing debate within political science, sociology and psychology. Self-evidently, a self-selection effect occurs: actors with specific background characteristics are more likely to become politically active than others. Without a minimal level of political knowledge or political efficacy, it is hard to imagine how anyone might get involved in

\section{Corresponding author:}

Marc Hooghe, Department of Political Science, University of Leuven, Parkstraat 45, B-3000 Leuven, Belgium

Email: Marc.Hooghe@soc.kuleuven.be 
politics in the first place (Prewitt, 1965). The debate rather revolves around the question of whether an additional socialization effects occurs, as was already predicted in the classical writings of de Tocqueville. Some authors have claimed that these socialization effects can be powerful, and that participants will develop a more pro-social value pattern because of the interaction with likeminded others (Putnam, 1993). Others, however, are much more skeptical about the claim that civic engagement exerts an additional socialization effect, over and above the effects of selfselection (Uslaner, 2002).

During the past decade, various authors have tried to disentangle the empirical merits of both approaches with varying degrees of success. A number of studies have highlighted the fact that the relationship between participation and attitudes is reciprocal (Brehm and Rahn, 1997), but it is hard to consider this as a final answer to the research question, since the aim is still to determine which one of the two effects is stronger. Arriving at a better understanding of the reciprocal relationship between participation and attitudes ideally requires panel data, allowing the researcher to track the development of attitudinal patterns among participants and passive citizens over an extended period of time with preferably multiple measurements (Finkel ,1985).

In this article, we report on a two-year panel study among late adolescents in Belgium who were questioned twice about their participation habits and political attitudes. Focusing on adolescents has an additional advantage since we can assume that their attitudes and value patterns are still being developed (Flanagan, 2004; Sapiro, 2004). The study of adolescents therefore allows us to maximize the likelihood that any socialization effects can be detected.

We also take the argument a step further by introducing a distinction between various forms of political participation. While some forms of participation involve active interaction with others, other forms of participation are usually performed in an individual manner. Checkbook activists write their checks at home, not in the company of other like-minded participants. Basically, the socialization perspective focuses on the role of face-to-face interaction: building on the insights gained from small-group research, it is expected that interaction with other like-minded actors has an effect on motivations and attitudes (Eder and Nenga, 2003; Verba, 1961). The presence of others serves as a motivational stimulus to develop specific and group-sanctioned preferences and attitudes. If this form of intensive interaction does not occur, it is assumed that socialization effects will remain shallow. Our panel design, and the different measures of political participation that are present in the survey, therefore allow us to conduct an even stricter test of the socialization thesis: we can assume that collective forms of participation, involving interaction with others, will have more profound effects on attitudes than individual forms of participation where there is no interaction with other actors.

In this article, we first briefly review the literature on the reciprocal relationship between selfselection and socialization. Based on this review we present three hypotheses that will guide us through the analysis. Subsequently we present data, methods and the operationalization of the data before moving on to the cross-lagged analysis of the panel data. This article closes with a brief discussion of the results and implications of the findings.

\section{Literature}

In the literature, there is little doubt about the observation that citizens participating in civic and political life on average are more civic-minded and display higher levels of political trust than passive citizens (Almond and Verba, 1963; Barnes and Kaase, 1979). Claims about the direction of causality between both phenomena were largely absent in the empirical literature of the 1970s. 
The socialization perspective, however, again came to the for by the publication of Putnam's 1993 study on civic traditions in modern Italy. In this work, the assumed causal order mainly flows from joining an association toward adhering to a democratic value pattern: 'Taking part in a choral society or a bird-watching club can teach self-discipline and an appreciation for the joys of successful collaboration' (Putnam, 1993: 90). Although this strong claim was later abandoned, in much of the research literature that tried to validate Putnam's findings, it was assumed that democratic value patterns would originate as a result of the interaction within various forms of voluntary associations. Basically, this expectation depends on a two-step process. It is assumed that members will first develop a more positive attitude toward their fellow members and that subsequently this attitude will be transferred toward society as a whole (Stolle, 1998). This assumption responds to the notion that was originally developed by de Tocqueville, claiming that civic engagement will serve to widen social identification and interest in the life of others. While the focus of individual citizens usually remains limited to their own private sphere, civic engagement allows citizens to develop a broader perspective, which results in an enhanced willingness to take into account the views of others. The capability for empathy, altruism, solidarity and reciprocity is developed as a result of the interaction that is associated with civic engagement (Paxton, 2007). There is also psychological support for this mechanism, as it can be assumed that actors that are involved in a specific form of behavior, e.g., pro-social behavior within a voluntary association, will be inclined to develop a congruent value pattern in order to avoid cognitive dissonance (Harmon-Jones and Harmon-Jones, 2002).

While the socialization perspective is appealing from this psychological perspective, it has also been confronted with a number of empirical shortcomings. First of all, it has to be remembered that the findings of empirical research are often disappointing. Most of this research has focused on the relationship between membership in voluntary associations and the development of generalized trust. While trust and membership are mostly positively related, in quite a number of studies the relationship proves not to be significant after including all the relevant control variables (Nannestad, 2008). Even more troubling is that we lack a good understanding of the causal mechanism that might explain the process of socialization. The existing body of social-psychological research on group processes does not support the claim that interaction with like-minded others would automatically serve to develop pro-social attitudes. It has been shown that this form of interaction will only lead to a strengthening of pre-existing attitudes, in line with the general consensus within the group. Group members will develop those attitudes that are supported by and are most strongly prevalent within the group (Haslam, 2001; Hooghe, 2003b).

In contrast to the socialization perspective stands the self-selection thesis. The main argument of these authors is that we are confronted with a problem of endogeneity. It is claimed that the observed relationship between democratic attitudes and participation can fully be explained by a self-selection effect: those who are already most democratically minded will tend to participate more intensively (Newton, 1997; Uslaner, 2002). Given the existing literature on the stability of attitudinal patterns in adulthood, it is rather unlikely that the main value orientations of a participant or a member will undergo further change as a result of civic engagement experiences. A basic assumption within the life cycle perspective is that the most important political attitudes are shaped relatively early, and that they will remain stable in subsequent phases of a life cycle.

There can be little doubt that self-selection does occur. We know that civic engagement is distributed unevenly across society. Not only are there strong patterns of inequality and stratification, but it is also more than likely that those with high trust, knowledge and efficacy levels will participate more intensively. The research question, rather, is to determine whether, following this process of self-selection, additional socialization effects occur. As a solution to this problem, 
Hooghe (2003b) has proposed a selection-and-adaptation mechanism: because of processes of self-selection, specific interaction contexts are being created and subsequently members adapt to the prevalent value patterns within these contexts. It has to be noted, however, that this study too was based on cross-sectional data, and therefore it could not deliver any final proof on the occurrence of this mechanism.

\section{Current research}

While the debate between proponents of the self-selection and the socialization thesis has been going on for over more than a decade by now, it is safe to claim that researchers have not reached a consensus. The main empirical obstacle for doing so is that most studies are based on crosssectional observations, and these do not permit disentangling causal effects. Finkel (1985) earlier summarized the research by stating that it leads to the conclusion that the relationship between participation and attitudes is reciprocal. The seminal study by Brehm and Rahn (1997) demonstrated a reciprocal relationship between trust and participation. Claassen (2008) has shown that participation in electoral campaigns is associated with a subsequent stronger feeling of party identification. Leighley (1991) demonstrated that taking part in specific forms of political participation is associated with a more sophisticated conceptualization of political matters. Valentino et al. (2009) have shown that participation leads to an enhancement of feelings of internal efficacy. There is empirical support, therefore, for both theoretical expectations.

To complicate things further, we also know that forms of participation have changed substantially in recent decades (Dalton, 2007). Traditional mass-based organizations involving intensive face-to-face interaction are in decline, being replaced by more individualized forms of political action, like checkbook activism or political consumerism (van Deth and Maloney, 2011). However, it is precisely these traditional forms that are expected to be most conducive to the occurrence of socialization effects and their waning therefore could have a negative effect on the socializing impact of civil society as a whole (Pattie et al., 2003). It is a general expectation that passive forms of membership, or forms of checkbook activism, will not lead to strong socialization effects. As Maloney (2008: 316) notes: 'Clearly, the social capital building potential of such involvement is limited.'

Not all authors agree, however, with this pessimistic outlook on the effects of passive or individualized membership. Wollebaek and Selle (2003) have made a strong claim that even passive membership, or any other form of participation that does not involve face-to-face interaction, might have strong socialization effects. Empirically, they demonstrate that in the Norwegian context passive membership (i.e. merely reading the magazine of an organization and paying membership dues) has just as powerful an effect on attitudes as active membership involving faceto-face interaction. With regard to the causality issue, however, the Wollebaek and Selle argument is not fully developed. The authors simply note that the relationship between attitudes and passive membership and attitudes is just as strong as the relationship between active membership and attitudes. Nonetheless, from the standard socialization perspective, it remains difficult to imagine how merely writing a check every year for a good cause might have an impact on attitudes.

\section{Social-psychological insights}

It has to be observed that this puzzle is not limited to the study of political participation or civic engagement. In various social sciences, the relationship between attitudes and behavior has been 
investigated in an intensive manner. These studies suggest that the correlation between attitudes and behaviors is far from perfect (Kraus, 1995). It can be assumed that - given various environmental restraints and opportunities - attitudes can predict future behavior to some extent (Ajzen and Fishbein, 2005). The reverse relationship, however, has been documented just as well, and within social psychology various causal mechanisms have been suggested to explain this observation (Olson and Stone, 2005). Especially relevant in this perspective has been the development of the action-based model of cognitive dissonance (Harmon-Jones and Harmon-Jones, 2002). The main idea of this approach is that actors will be inclined to reduce the forms of cognitive dissonance. As in Festinger's original formulation of the theory, it is assumed that preference adaptation follows behavioral patterns, since the actor is interested in continuing his or her behavioral preferences:

[T] he effect of action orientation on cognitive discrepancy reduction occurred because the action orientation assists individuals in transforming their decisions into effective and unconflicted action. By increasing the value of the chosen alternative and/or decreasing the value of the rejected alternative, individuals should be more able to effectively engage in actions that follow from their decisions. These changes in valuation thus should result in more ease in successfully enacting the decision-related behavior, which may then lead to more efficient and unconflicted behavior. (Harmon-Jones and Harmon-Jones, 2002: 721)

Applying the action-based model of cognitive dissonance to our specific topic, we can assume that once actors have participated in civic engagement, they will subsequently develop more positive evaluations of their behavioral choice, in order to allow them to continue their behavioral patterns in the most effective manner.

\section{Hypotheses}

Because we collected panel data specifically to test the relationship between participation and political attitudes, we can simultaneously test the extent of socialization and self-selection effects. Our first hypothesis is that actors with pro-social value patterns self-select into participation. The competing second hypothesis claims that participants are socialized as a result of their participation behavior. Although these hypotheses are to some extent contradictory, the current research design allows us to compare the strength of both effects.

Our first two hypotheses are visualized in Figure 1. First, we want to test whether respondents self-select into or are being socialized by political participation experiences. The arrow from attitudes ( $\mathrm{t} 1$ ) to participation ( $\mathrm{t} 2$ ) would lead to a conclusion about the importance of self-selection effects (indicated by a full line $\rightarrow$ ). A second possibility is that respondents participating in politics develop congruent political attitudes, as predicted by the socialization thesis (indicated by a dashed line $--\rightarrow$ ). As was noted in the review of the literature, a number of studies have demonstrated that the relationship between participation and attitudes is reciprocal. In this article we want to go a step further by testing which mechanism is stronger. This implies an additional test in order to observe whether there is a difference between the two effects that may be found, and, if so, whether this difference is statistically significant. This final question can be addressed by including an additional test. In the analysis we will determine which structural equation model has the best-fit indicators: the one in which socialization and self-selection effects are assumed to be equal, or the one in which the two effects are different. For reasons of clarity, in the results sections we will only report the best-fitting model. 


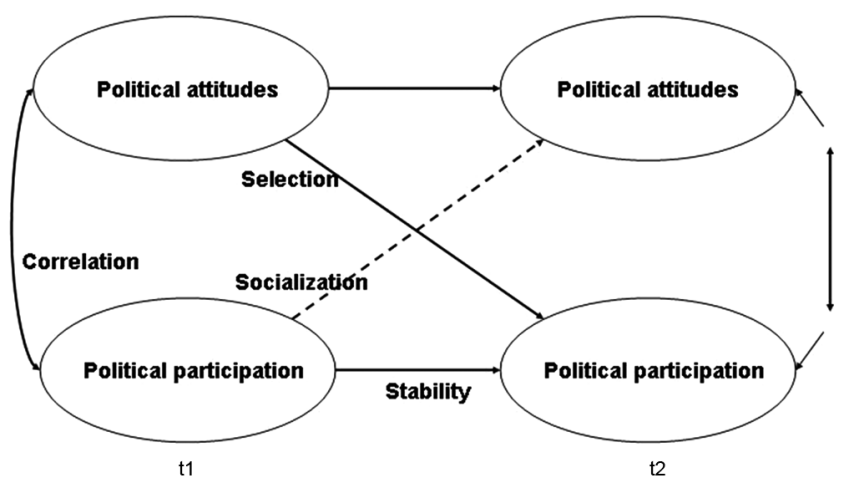

Figure I. Hypotheses: socialization and self-selection

Note: The observed indicators and autocorrelated errors are not displayed here for reasons of clarity.

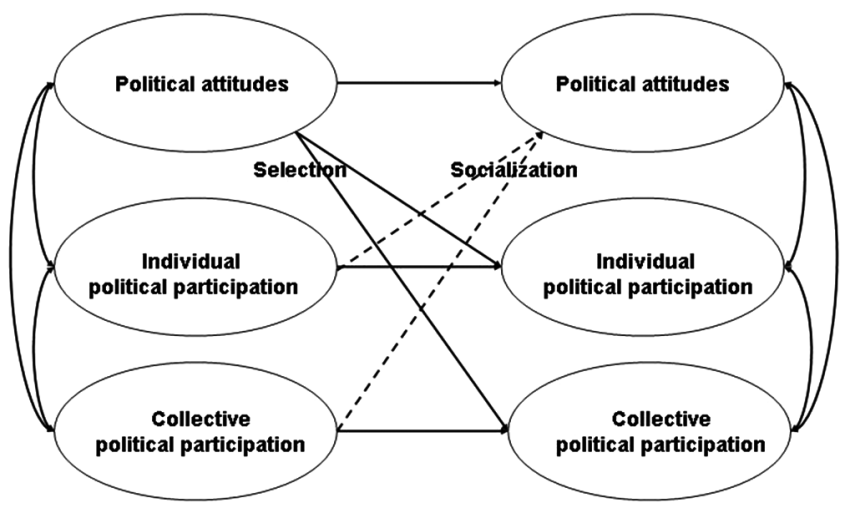

Figure 2. Effects of individual and collective participation

Note: The observed indicators and autocorrelated errors are not displayed here for reasons of clarity.

The third hypothesis guiding the research is that collective forms of engagement will have a stronger effect on value patterns than individual forms of action. This hypothesis follows the main assumption in research on civic engagement, which is that socialization effects occur as a result of interaction with other actors. The third hypothesis (Figure 2) that will be tested is whether collective political participation has more powerful effects on political attitudes than individual political participation $(--\rightarrow)$. As Putnam $(1993,2000)$ argues that collective processes have stronger and more lasting effects, we expect that the effects from collective political participation will be stronger than those from individual participation. ${ }^{1}$

\section{Data and methods}

For the current analysis we will use the results of the Belgian Political Panel Survey, 2006-2008 (BPPS, 2006-2008). These data are based on a two-wave panel study among sixteen- and eighteenyear-olds. In 2006, a representative survey was conducted among 6330 sixteen-year-olds in Belgium, and the response analysis demonstrated that the survey was representative for language, 
school type, gender and region. Based on written surveys completed by respondents in 112 schools, the study focused on young people's social and political attitudes and it contained questions about their participation habits. To obtain a national random sample, all schools included in the survey were selected through a stratified sample, based on the location and type of school. In each school, a minimum of fifty students were selected, representative of the tracks on offer in that school. The response rate was 66 per cent for the schools, and, within the schools, 99 per cent for the pupils. In 2008 , the respondents were surveyed for a second wave, this time at the age of eighteen. While most of the initial respondents could still be reached in school, for those who had left or changed schools, alternative strategies had to be developed. The two-year time frame was chosen because most students could still be surveyed in their schools two years later, as education is compulsory until age eighteen in Belgium. In these schools, the same classes were resurveyed and this allowed re-interviewing almost 3000 students. The other students were contacted through a mail survey. In total, 4235 pupils (or 67 per cent) from the initial panel were resurveyed. The attrition rate is in line with what we can expect for this kind of panel study. While this attrition rate is considerable, it has to be noted that the first wave was conducted in a school context, which could have led to the false assumption among pupils that participation was compulsory. A further analysis demonstrated that there were limited differences between the respondents who dropped out after the first wave and those who remained in the panel. For all the analyses reported in this article, we also checked whether there were significant differences between participants that were reached again in a school context and those that participated in the mail survey, but this proved not to be the case. Response analyses indicate that the panel data are representative for the eighteen-year-old age group within the Belgian population with regard to gender and educational track. This dataset provides us access to a total sample of 4235 panel respondents, who were interviewed both in 2006 (average age 15.7) and in 2008 (average age 17.7).

The goal of the current analysis is not to offer a full explanation of either participation or political attitudes. Therefore we do not conduct a fully elaborated analysis on either participation or attitudes. The goal of the present analysis is more limited as we want to investigate the reciprocal relationship between participation and attitudes. Therefore we use a cross-lagged structural equation model (see Figure 1). This kind of model allows us to ascertain the relationship between a limited number of latent or observed variables (Finkel, 2007). In this case we opted for a limited model, with only gender and socioeconomic status (operationalized by a factor scale of current level of education (track), educational goal and number of books at home) as control variables.

This is by no means the first study to use this kind of technique on panel data to ascertain reciprocal effects, most typically between attitudes and behavior (Claassen, 2008; Finkel, 1985, 1987; Leighley, 1991). Our ambition in this article is to go a step further. Following the literature on this topic, it is indeed likely that we will find reciprocal effects. Our main research question, however, is to determine what kind of effect is strongest. This test can be performed by adding a new test to the model, by trying to constrain the two cross-lagged effects to be equal. If the $\mathrm{Chi}^{2}$-difference test yields a significant difference, then this indicates that there are significant differences in the self-selection and socialization parameters. In that case an unconstrained model clearly should be preferred. An insignificant p-value, on the other hand, indicates that both models have a similar fit. In that case there is no statistically valid reason to assume that one relationship would be stronger than the other.

This kind of cross-lagged structural equation model leads to three kinds of estimated relations. Covariances depict the relationship between two simultaneous observations. Stability coefficients are measured between two observations of the same phenomenon at two different moments in time. Third, and most interesting from our perspective, are the cross-lagged effects between 
different variables at different moments of time. Although the cross-lagged effects imply some kind of causality (of attitudes on participation or vice versa), strictly speaking this model cannot prove causality as we only have two waves of panel data. To make firm causal statements, one needs at least three observations. Nevertheless, in most cases it will be difficult to argue that a variable measured later in time (at time $\mathrm{t}+1$ ) could be responsible for a phenomenon measured at an earlier time (at time $\mathrm{t}$ ).

\section{Operationalization: political participation and political attitudes}

\section{Political participation: individual and collective forms of participation}

In our models, we include two kinds of variables: political participation and attitudes. In this section we explain how both sets of variables have been operationalized (for a full list of variables, see Appendix 1). Political participation was measured by asking respondents how often they had participated during the last twelve months in a particular activity, with three possible responses: never, sometimes and often. Following our third hypothesis, we will make a distinction between individual and collective forms of political participation. As individual participation acts, we include all forms of participation that can be performed individually, contrasting them with collective forms of participation that necessarily have to be the result of a group-based process (van Deth and Maloney, 2011). Wearing a badge, signing a petition, contacting public officials, sending a political message, displaying a political message, donating money to non-governmental organizations and boycotting or buying specific products for political reasons will be considered as individual political action in this analysis, since all of these actions can be performed on an individual basis and they do not require the physical presence of other actors.

On the other hand, collective forms of political participation are defined as those forms of engagement that automatically imply the presence of others, that is to say participating in a demonstration or attending a political event. Being a member of a political party too is grouped in this category. The available evidence indeed suggests that party membership should not be seen as an individualized act, but should be seen as a form of belonging to a politicized micro-mobilization context (Scarrow and Gezgor, 2010). The assumption here is that demonstrations, political events and political parties will always have an $n>1$ audience. As both collective and individual political participation are theoretically distinct concepts, their dimensionality was tested using confirmatory factor analysis, as well as the equivalence over time (Pitts et al., 1996; Schlueter and Davidov, 2007; see Appendix 2). These tests lead to the conclusion that both latent concepts are measured in a valid manner over time. ${ }^{2}$

As can be observed in Table 1, both in 2006 and in 2008, signing a petition, boycotting and buycotting products and donating money to 'good causes' are the most prevalent forms of participation among late adolescents. For protest marches, attendance was roughly equal in 2006 and 2008. Late adolescents tend to score quite high on various measurements of political participation (Quintelier, 2008). This implies that it does make sense to study the consequences of participation, even among this age group.

\section{Political attitudes: political interest and political trust}

For political attitudes, we selected two basic attitudes that figured prominently earlier in the work of Almond and Verba (1963) on the 'civic culture': political interest and political trust. A first political attitude that will be assessed is political interest. Political interest is measured by just one 
Table I. Frequency of participation acts among late adolescents

\begin{tabular}{|c|c|c|c|c|c|c|}
\hline & \multicolumn{3}{|l|}{2006} & \multicolumn{3}{|l|}{2008} \\
\hline & Never & Sometimes & Often & Never & Sometimes & Often \\
\hline \multicolumn{7}{|l|}{ Individual } \\
\hline Wearing a badge & 84.4 & 13.6 & 2.0 & 81.7 & 15.8 & 2.5 \\
\hline Signing a petition & 58.9 & 39.2 & 1.9 & 54.9 & 42.8 & 2.2 \\
\hline Contacting public officials & 96.5 & 3.0 & 0.5 & 84.5 & 14.7 & 0.9 \\
\hline Sending a political message & 88.0 & 10.6 & 1.4 & 94.4 & 3.1 & 0.5 \\
\hline Donating money & 54.7 & 42.1 & 3.1 & 55.8 & 41.4 & 2.8 \\
\hline Boycotting products & 80.3 & 15.4 & 4.3 & 77.0 & 18.3 & 4.7 \\
\hline Displaying message & 95.6 & 3.7 & 0.7 & 83.6 & 14.6 & 1.8 \\
\hline Buycotting products & 79.9 & 16.6 & 3.5 & 74.0 & 21.6 & 4.4 \\
\hline \multicolumn{7}{|l|}{ Collective } \\
\hline Being a party member* & 98.8 & na & 1.2 & 98.5 & na & 1.5 \\
\hline Participating in a protest march & 89.6 & 9.6 & 0.8 & 90.7 & 8.6 & 0.7 \\
\hline $\begin{array}{l}\text { Attending a show with political } \\
\text { content }\end{array}$ & 86.5 & 12.7 & 0.8 & 94.6 & 4.3 & 1.1 \\
\hline
\end{tabular}

Notes: * Dummy variable: $0=$ no/never; I = yes/often. na: not available. Entries are frequencies of participation in that particular activity.

Source: Belgian Political Panel Survey (BPPS), 2006-2008, $n=4325$.

survey item: 'In general, how interested are you in politics?' The possible responses are 'not at all interested', 'a little interested', 'interested' or 'very interested'. As this is a single item, there is no sense in capturing equivalence across the two observations. A second attitude is political trust. Political trust was measured by asking respondents about their trust level in several political institutions (federal parliament, provincial parliament, police, government, political parties, courts) (range: $0-10$ ). Both in 2006 and 2008 this proved to be an equivalent and one-dimensional scale (Appendix 3).

In the analysis, we ascertain the effect of individual and collective political participation on these two political attitudes. We will estimate the model as presented in Figure 2, and ascertain whether cross-lagged effects are present, and if so, whether they differ significantly from one another (hypotheses 1 and 2). Subsequently, the distinction between individual and collective participation should allow us to disentangle the effects of both forms of participation (hypothesis 3 ).

\section{Results: political interest}

First, we explore the relationship between participation and political interest. We started by determining whether self-selection and socialization effects are significantly different for individual political participation. This proved to be the case: we observed significant differences in the model fit of an unconstrained model (allowing self-selection and socialization effects to differ) compared to a constrained model (where both effects are constrained to be equal). Because of this significant difference, the conclusion is that the cross-lagged effects cannot be constrained to be equal $\left(\mathrm{Chi}^{2} \Delta\right.$ $=46.007, \mathrm{df}=1, \mathrm{p}<0.001)$. This demonstrates that one effect is significantly stronger than the other one. ${ }^{3}$

The tables represent the coefficients obtained by means of a model as depicted in Figure 1. In Table 2, we present the stability coefficients, cross-lagged effects and covariances for individual 
Table 2. Relationship between individual political participation and political interest

\begin{tabular}{llll}
\hline & $\begin{array}{l}2006 \\
\text { Individual political } \\
\text { participation }\end{array}$ & $\begin{array}{l}2008 \\
\text { Political interest }\end{array}$ & $\begin{array}{l}2008 \\
\text { Individual political } \\
\text { participation }\end{array}$ \\
\hline 2006 & & $0.268(0.031)$ & $0.751(0.037)$ \\
Individual political participation & - & $\begin{array}{l}\mathbf{0 . 2 0 9 * * *} \\
0.344(0.016)\end{array}$ & $\begin{array}{l}\mathbf{0 . 0 2 2}(0.020) \\
\text { Political interest }\end{array}$ \\
2008 & $0.170(0.01 \mathrm{II})$ & $0.326^{* * *}$ & $\mathbf{0 . 0 2 6 \mathrm { ns }}$ \\
Political interest & $0.383^{* * *}$ & - & $0.116(0.010)$ \\
Explained variance & - & 0.285 & $0.409 * * *$ \\
\hline
\end{tabular}

Notes: WLSMV estimation. Entries are unstandardized effects (std errors), standardized effects and significances. Cross-lagged effects in bold. Sign: *:p <.05; **:p <.0I; ***:p <.00I. Chi²-value: 764.699; df: I20***; CFI: 0.955; RMSEA: 0.036. Control variables: gender, socioeconomic status.

Source: BPPS, 2006-2008, $n=4165$.

political participation. Furthermore, goodness-of-fit indices are presented, as well as the explained variance. First, the covariances between political interest and individual political participation are quite high (standardized effects of $0.383^{* * *}$ in 2006 and $0.409^{* * *}$ in 2008). This indicates that both are related: those with interest are more likely to participate and vice versa, but this hardly comes as a surprise. Second, the stability coefficients indicate the persistence of political interest $\left(0.326^{* * *}\right)$ and individual political participation $\left(0.726^{* * *}\right)$ over this two-year period. Third, the cross-lagged effects - which are our main interest - test whether attitudes stimulate behavior or vice versa. The effect of individual political participation in 2006 on political interest in 2008 is larger $\left(0.209^{* * *}\right)$ than the effect of political interest in 2006 on individual participation in 2008 $(0.026 \mathrm{~ns})$. This indicates that participation stimulates political interest. Actors involved in individual political participation are inclined to develop a stronger sense of political interest after they have participated. This effect is significantly stronger than the self-selection effect.

If we perform the same analysis for collective political participation, comparable parameter estimates are found. By comparing constrained and unconstrained models, we can again conclude that both cross-lagged effects are significantly different $\left(\mathrm{Chi}^{2} \Delta=13.572, \mathrm{df}=1, \mathrm{p}<0.001\right)$. The analysis demonstrates that collective political participation (2006) has a positive effect on political interest (2008), with a standardized coefficient of $0.156^{* * *}$ (Table 3). Political interest, on the other hand, does not seem to have a significant effect on collective political participation $(-0.030 \mathrm{~ns})$. For collective political action, too, we can conclude that the socialization effect is significantly stronger than the self-selection effect. The conclusion therefore must be that adolescents tend to develop political interest after they begin to participate, not prior to it.

\section{Results: political trust}

For political trust, we proceed in exactly the same manner as with political interest. For individual political participation, we first demonstrated that both effects are significantly different from one another $\left(\mathrm{Chi}^{2} \Delta=5.616, \mathrm{df}=1, \mathrm{p}<0.01\right)$. Table 4 presents the relationship between individual political participation and political trust. Although one might theoretically expect that political trust and political participation are intertwined, this relationship is quite modest. While in 2006 
Table 3. Relationship between collective political participation and political interest

\begin{tabular}{|c|c|c|c|}
\hline To: & $\begin{array}{l}2006 \\
\text { Collective political } \\
\text { participation }\end{array}$ & $\begin{array}{l}2008 \\
\text { Political interest }\end{array}$ & $\begin{array}{l}2008 \\
\text { Collective political } \\
\text { participation }\end{array}$ \\
\hline \multicolumn{4}{|l|}{2006} \\
\hline Collective political participation & - & $\begin{array}{l}0.240(0.061) \\
0.156 * * *\end{array}$ & $\begin{array}{l}0.769(0.1 \mathrm{II}) \\
0.684^{* * * *}\end{array}$ \\
\hline Political interest & $\begin{array}{l}0.164(0.015) \\
0.416 * * *\end{array}$ & $\begin{array}{l}0.355(0.023) \\
0.336 * * *\end{array}$ & $\begin{array}{l}-0.023(0.040) \\
-0.030 \mathrm{~ns}\end{array}$ \\
\hline 2008 & & & \\
\hline Political interest & - & - & $\begin{array}{l}0.093(0.015) \\
0.304^{* * * *}\end{array}$ \\
\hline Explained variance & 0.038 & 0.272 & 0.480 \\
\hline
\end{tabular}

Notes: WLSMV estimation. Entries are unstandardized effects (std errors), standardized effects and significances.

Cross-lagged effects in bold. Sign: *:p <.05; **:p <.0I; ***:p <.00I. Chi²-value: 50.796; df: 23***; CFI: 0.989; RMSEA:

0.017 . Control variables: gender, socioeconomic status.

Source: BPPS, 2006-2008, $n=4165$.

Table 4. Relationship between individual political participation and political trust

\begin{tabular}{|c|c|c|c|}
\hline To: & $\begin{array}{l}2006 \\
\text { Individual political } \\
\text { participation }\end{array}$ & $\begin{array}{l}2008 \\
\text { Political trust }\end{array}$ & $\begin{array}{l}2008 \\
\text { Individual political } \\
\text { participation }\end{array}$ \\
\hline \multicolumn{4}{|l|}{2006} \\
\hline Individual political participation & - & $\begin{array}{l}0.175(0.070) \\
0.055^{*}\end{array}$ & $\begin{array}{l}0.760(0.032) \\
0.735 * * *\end{array}$ \\
\hline Political trust & $\begin{array}{l}-0.010(0.030) \\
-0.008 \mathrm{~ns}\end{array}$ & $\begin{array}{l}0.440(0.015) \\
0.464^{* * *}\end{array}$ & $\begin{array}{l}0.010(0.006) \\
0.032 \mathrm{~ns}\end{array}$ \\
\hline 2008 & & & \\
\hline Political trust & - & - & $\begin{array}{l}-0.018(0.023) \\
-0.025 \mathrm{~ns}\end{array}$ \\
\hline Explained variance & 0.149 & 0.274 & 0.620 \\
\hline
\end{tabular}

Notes: WLSMV Estimation. Entries are unstandardized effects (std errors), standardized effects and significances. Cross-lagged effects in bold. Sign: ${ }^{*}: \mathrm{p}<.05 ;{ }^{* *}: \mathrm{p}<.0$ I; ${ }^{* * *}: \mathrm{p}<.00$ I. Chi ${ }^{2}$-value: I610.147; df: 332***; CFI: 0.945; RMSEA: 0.030 . Control variables: gender, socioeconomic status.

Source: BPPS, 2006-2008, $n=4165$.

there is still a small correlation, this relationship is not significant in 2008. Apparently, political trust is not related to individual participation, at least not among this age group. Second, the stability coefficients indicate that political trust is rather stable during the observation period $(0.464 * * *)$. One can observe that the cross-lagged effects between individual political participation and political trust are rather small, with coefficients of $0.055^{*}$ and $0.032 \mathrm{~ns}$, but as already mentioned, this difference is still significant. Therefore, the effect of individual political participation (2006) on political trust (2008) is significantly stronger than the effect of political trust (2006) on individual political participation (2008).

The relationship between collective political participation and trust is rather disappointing. In this case, there was no difference between the constrained and unconstrained model $\left(\mathrm{Chi}^{2} \Delta=1.433\right.$, 
Table 5. Relationship between collective political participation and political trust

\begin{tabular}{|c|c|c|c|}
\hline To: & $\begin{array}{l}2006 \\
\text { Collective political } \\
\text { participation }\end{array}$ & $\begin{array}{l}2008 \\
\text { Political trust }\end{array}$ & $\begin{array}{l}2008 \\
\text { Collective political } \\
\text { participation }\end{array}$ \\
\hline \multicolumn{4}{|l|}{2006} \\
\hline Collective political participation & - & $\begin{array}{l}0.002(0.014) \\
0.006 \mathrm{~ns}\end{array}$ & $\begin{array}{l}0.793(0.1 \mid 3) \\
0.695^{* * *}\end{array}$ \\
\hline Political trust & $\begin{array}{l}0.172(0.049) \\
0.011 * * *\end{array}$ & $\begin{array}{l}0.440(0.015) \\
0.464 * * *\end{array}$ & $\begin{array}{l}0.002(0.014) \\
0.000 \mathrm{~ns}\end{array}$ \\
\hline 2008 & & & \\
\hline Political trust & - & - & $\begin{array}{l}0.009(0.049) \\
0.00 \mathrm{Ins}\end{array}$ \\
\hline Explained variance & 0.020 & 0.051 & 0.271 \\
\hline
\end{tabular}

Notes: WLSMV Estimation. Entries are unstandardized effects (std errors), standardized effects and significances. Cross-lagged effects in bold. Sign: *:p <.05; **:p <.0I; ***:p <.00I. Chi²-value: 82 I.I23; df: I56***; CFI: 0.954; RMSEA: 0.032 . Control variables: gender, socioeconomic status.

Source: BPPS, 2006-2008, n = 4I65.

$\mathrm{df}=1, \mathrm{p}>0.05){ }^{4}$ The results reported in Table 5 make clear why this is so: both cross-lagged effects are non-significant. The conclusion therefore is that there is no significant relationship between political trust and collective action, no matter the direction of causality.

\section{Individual and collective participation}

Table 2 through to Table 5 told us a rather complicated story, and considering our hypotheses it is important that we keep a clear eye on the major theoretical focus. We investigated four different possible relationships (between individual and collective participation, on the one hand, and between political interest and political trust, on the other hand). In three out of four cases, the socialization effect was significantly stronger than the self-selection effect. In the fourth case (the relationship between collective participation and political trust), all relations were non-significant. The effects that we observed are therefore in line with the socialization perspective and its psychological underpinning in the action-based dissonance theory: once actors perform specific actions, they are more likely to develop attitudes that are in line with their behavior. Hypotheses 1 and 2 are therefore both confirmed, but the evidence in favor of hypothesis 2 (socialization effect) is significantly stronger than the one for the occurrence of the self-selection effect.

Hypothesis 3, on the differential effect on individual and collective participation, on the other hand, was not confirmed. A final judgment on hypothesis 3, however, requires an additional test (Figure 2). To test the different effects, the separate models for individual and collective political participation are combined into a single model for each attitude. It is subsequently tested to see whether the model fit significantly deviates if: (1) the socialization effects are constrained to be equal (the effect of individual/collective political participation on the political attitudes); and (2) if the self-selection effects (the effect of the political attitudes on individual/collective political participation) are constrained to be equal. Basically, we perform the same significance test here as we did earlier, but we now focus on the difference between individual and collective participation, in order to test hypothesis 3. Given the fact that the results of these new models again are not meaningful by themselves, we only present the fit of the models (Table 6), as they will suggest whether the observed differences are significant or not. 
Table 6. Comparison of goodness of fit indices for selection and socialization effects

\begin{tabular}{|c|c|c|c|c|c|}
\hline Model & $\mathrm{Chi}^{2}$ & Df & $\mathrm{P}$-value & $\mathrm{CFI}$ & RMSEA \\
\hline \multicolumn{6}{|l|}{ Political interest } \\
\hline Baseline model & 732.643 & 193 & 0.000 & 0.968 & 0.026 \\
\hline $\begin{array}{l}\text { Self-selection effects } \\
\text { constrained to be equal }\end{array}$ & 733.878 & 194 & 0.000 & 0.968 & 0.026 \\
\hline Chi ${ }^{2}$-difference & 0.629 & I & $0.428(\mathrm{~ns})$ & & \\
\hline $\begin{array}{l}\text { Socialization effects } \\
\text { constrained to be equal }\end{array}$ & 736.823 & 195 & 0.000 & 0.968 & 0.026 \\
\hline Chi²-difference & 4.480 & 2 & $0.106(\mathrm{~ns})$ & & \\
\hline \multicolumn{6}{|l|}{ Political trust } \\
\hline Baseline model & 1944.540 & 443 & 0.000 & 0.941 & 0.028 \\
\hline $\begin{array}{l}\text { Self-selection effects } \\
\text { constrained to be equal }\end{array}$ & 1937.935 & 444 & 0.000 & 0.935 & 0.028 \\
\hline $\mathrm{Chi}^{2}$-difference & 0.965 & I & $0.32 \mathrm{I}(\mathrm{ns})$ & & \\
\hline $\begin{array}{l}\text { Socialization effects } \\
\text { constrained to be equal }\end{array}$ & 1935.410 & 445 & 0.000 & 0.942 & 0.028 \\
\hline $\mathrm{Chi}^{2}$-difference & 4.514 & 2 & $0.105(\mathrm{~ns})$ & & \\
\hline
\end{tabular}

Note: Entries are the test characteristics of six different models (full results available from the authors), with baseline models (Tables 2-5), and models with equal self-selection and equal socialization effects for individual and collective participation acts.

In the first variation of the original model, it is assumed that the self-selection effects of political interest on individual and collective participation are equal; in the second variation it is assumed that the socialization effects for both forms of participation are equal. Looking at the model fit comparisons of the models for both political attitudes, we find no significant differences. This indicates that the effects of individual and collective participation on political interest are not significantly different. For political trust too we do not find any significant differences. Hypothesis 3 is therefore not confirmed: individual participation has equally strong socialization effects as collective participation.

\section{Discussion}

In this article, we have tried to shed new light on the ongoing discussion about the merits of the self-selection and the socialization thesis with regard to political participation. While earlier studies have described this relationship as reciprocal, we wanted to go a step further in order to determine the direction in which the relationship is stronger. We did so by reporting on the results of a panel study among late adolescents in Belgium. Of course, we must acknowledge the limitations of the present study. The fact that we focus on late adolescents has both advantages and disadvantages. The advantage is that among late adolescents, it is quite likely that political attitudes are less stable than among an adult sample (Kraus, 1995:69). If there is a group in which we can hope to detect attitudinal changes, it is exactly late adolescents. On the other hand, there is also a disadvantage: as this group has not yet reached voting age, it is likely that some forms of political participation are not yet accessible to them. Yet, as we have seen in Table 1, this age group is quite active in various forms of participation, which produces sufficient variance on these measurements.

With regard to our first two hypotheses, it is clear that we find stronger support for the socialization thesis than for the self-selection thesis. The relationship might be reciprocal, but the arrow is significantly stronger in one direction than in the other. Yet, these findings too have to be 
qualified. First, it could be argued that we only have data on late adolescents. One could question whether the same results could be obtained among adults, as we can assume that their value patterns are already firmly established. While there is some merit to this point, two comments can be made. First, our observation period was only two years. While it might be true that among adults socialization processes are less powerful, they can stretch over longer periods of time. Second, earlier research among adults using recall questions about previous participation experiences has shown that participation experiences at a young age tend to have persistent effects, even among adults (Hooghe, 2003a; Jennings, 1987). Not only do they inaugurate persistent participation habits that can continue throughout the life cycle, but it has also been shown that the attitudinal effects of previous participation experiences are at least as powerful as the effects of current participation habits. One can conclude therefore that there is no reason why political learning processes would be completely absent among adults (Sigel, 1989). Studying citizens at a young age, therefore, certainly can be seen as a valid research strategy if one wants to detect life-long political learning processes.

The third hypothesis, on the effect of individual and collective participation experiences was not supported at all. Some of the socio-psychological mechanisms that we suggested in the review of the literature might be helpful to explain these findings. In line with action-based dissonance theory, we can assume that those who are politically active will be inclined to develop more positive attitudes toward the political system. It makes little sense to spend time and other resources on engagement if at the same time one expresses no interest at all in politics. The action-based dissonance approach would suggest that actors will adapt their attitudes in order to be in accordance with their prior decisions and behavioral patterns. This mechanism seems to occur, no matter whether there is a presence, and possibly peer pressure of like-minded others, or whether the participation act is performed in an individual setting. Indeed, dissonance theories assume that actors do not just want to create a favorable impression toward the outside world, but that they also want to achieve congruence between their actions and their own internal motivations, and therefore the presence of other actors does not make a difference in this regard.

The current findings are completely in line with action-based dissonance theory: once actors are involved in a form of behavior, they will have a tendency to develop congruent attitudes. Of course, other causal mechanisms might be suggested too. Youniss (1980) has introduced the idea of the development of a 'responsible citizen' role that is quite compatible with the action-based dissonance theory. During late adolescence, participants learn to view themselves as responsible members of a community and they adopt and internalize this role. If they are engaged in all kinds of activities and organizations, they will be inclined to develop the value patterns that are compatible with this role. Participation experiences might also lead to a feeling of empowerment: the act of participation itself might teach participants that they can actually change things and improve living conditions, even if only on a very small scale. This process should result in a more positive evaluation of the political system as a whole. The sour grapes phenomenon is well known; it can be expected that those who do not participate in civic life will develop more negative attitudes toward the political system. In the present study, one could state that a 'sweet grapes' phenomenon occurs just as well. Those who participate at the age of 16 subsequently develop a more positive attitude toward the political system. We do not wish to enter into a purely behaviorist approach toward political participation, but it is clear that participation by itself might lead to attitudinal outcomes. Earlier research has shown that compulsory forms of community service during high school years can have positive effects on subsequent willingness to engage in this form of behavior on a voluntary basis (Metz and Youniss, 2005). In the current study a similar phenomenon has been documented: prior engagement levels lead to subsequent attitudinal outcomes. 
For participation research, the current analysis raises new and fundamental questions. It seems well established that mass-based forms of participation are in decline, while individual acts of engagement are on the rise, especially among younger age groups. Usually, this trend is seen as problematic, as the standard approach toward socialization cannot explain why individual acts should have attitudinal consequences. The current analysis suggests that this concern is unfounded: individual participation is just as important as collective action. The precise causal mechanisms still needs to be developed further, but in the current phase of the research, there is no reason to be overly concerned about the rise of individual participation acts. If the socialization effects of political participation are indeed mainly dependent on internal psychological mechanisms as described by various developments of dissonance theory, the presence of others should not be considered as an essential catalyzing role for this process to occur. Obviously this does not mean that some of the other consequences of the trend toward individualized participation should not be further investigated. Individualized acts of participation can indeed have specific consequences with regard to the representativeness of political participation, or with regard to reaching a form of interest aggregation. For these elements, it indeed remains to be investigated whether individualized of participation offer a functional equivalent for the more classic forms of collective participation. For socialization effects, however, that since the work of de Tocqueville have been seen as a major social effect of participation, we do not find a reason to prefer collective over individualized participation.

Appendix I. Descriptives of the variables being used

\begin{tabular}{|c|c|c|c|c|c|c|c|}
\hline & \multirow[t]{2}{*}{ Range } & \multicolumn{3}{|l|}{2006} & \multicolumn{3}{|l|}{2008} \\
\hline & & Missing & Mean & $\begin{array}{l}\text { Std } \\
\text { dev }\end{array}$ & Missing & Mean & $\begin{array}{l}\text { Std } \\
\text { dev }\end{array}$ \\
\hline \multicolumn{8}{|l|}{ Individual } \\
\hline Wearing a badge & $0-2$ & 37 & 0.176 & 0.430 & 36 & 0.208 & 0.463 \\
\hline Signing a petition & $0-2$ & 30 & 0.429 & 0.532 & 28 & 0.473 & 0.542 \\
\hline Contacting public officials & $0-2$ & 36 & 0.040 & 0.220 & 33 & 0.062 & 0.261 \\
\hline Sending a political message & $0-2$ & 36 & 0.133 & 0.378 & 35 & 0.181 & 0.429 \\
\hline Donating money & $0-2$ & 41 & 0.484 & 0.559 & 36 & 0.470 & 0.552 \\
\hline Boycotting products & $0-2$ & 42 & 0.241 & 0.519 & 29 & 0.277 & 0.543 \\
\hline Displaying message & $0-2$ & 50 & 0.051 & 0.252 & 37 & 0.064 & 0.286 \\
\hline Buycotting products & $0-2$ & 50 & 0.236 & 0.501 & 30 & 0.304 & 0.547 \\
\hline \multicolumn{8}{|l|}{ Collective } \\
\hline Being a party member & $0-1$ & 51 & 0.007 & 0.082 & 20 & 0.015 & 0.121 \\
\hline Participating in a protest march & $0-2$ & 38 & 0.112 & 0.339 & 30 & 0.100 & 0.321 \\
\hline $\begin{array}{l}\text { Attending a show with cultural } \\
\text { content }\end{array}$ & $0-2$ & 34 & 0.143 & 0.372 & 34 & 0.164 & 0.394 \\
\hline Political interest & $\mathrm{I}-4$ & 29 & 2.005 & 0.782 & 24 & 2.181 & 0.825 \\
\hline \multicolumn{8}{|l|}{ Trust in ... } \\
\hline Police & $0-10$ & 43 & 5.402 & 2.479 & 26 & 5.751 & 2.346 \\
\hline Courts & $0-10$ & 65 & 5.689 & 2.393 & 34 & 6.043 & 2.253 \\
\hline Federal parliament & $0-10$ & 147 & 4.902 & 2.320 & 46 & 4.881 & 2.271 \\
\hline Provincial parliament & $0-10$ & 148 & 4.986 & 2.289 & 45 & 5.137 & 2.241 \\
\hline Government & $0-10$ & 134 & 5.158 & 2.408 & 44 & 4.573 & 2.389 \\
\hline Political parties & $0-10$ & 120 & 4.219 & 2.356 & 36 & 4.191 & 2.213 \\
\hline Gender & $0-1$ & 49 & 0.490 & 0.500 & \multicolumn{3}{|c|}{ Only 2006 data used } \\
\hline Socioeconomic status & $-2.230-1.244$ & 21 & 0.093 & 0.827 & \multicolumn{3}{|c|}{ Only 2006 data used } \\
\hline
\end{tabular}


Appendix 2. Equivalence of factor structure of political participation

Individual political participation: equivalence test

\begin{tabular}{llllll}
\hline Model & Chi $^{2}$ & Df & p-value & CFI & RMSEA \\
\hline Unconstrained factor loadings & 518.943 & 34 & 0.000 & 0.949 & 0.058 \\
Constrained factor loadings & 426.254 & 40 & 0.0000 & 0.959 & 0.048 \\
Chi ${ }^{2}$ difference test & 3.744 & $6^{*}$ & 0.7112 & & \\
\hline
\end{tabular}

Notes: * Factor loading of wearing a badge constrained at I.

Unstandardized factor loadings individual political participation

\begin{tabular}{|c|c|c|c|c|c|c|}
\hline & \multicolumn{2}{|c|}{$\begin{array}{l}\text { Unconstrained } \\
2006\end{array}$} & \multicolumn{2}{|c|}{$\begin{array}{l}\text { Unconstrained } \\
2008\end{array}$} & \multicolumn{2}{|c|}{ Constrained } \\
\hline & Estimate & SE & Estimate & SE & Estimate & SE \\
\hline Wearing a badge & 1.000 & 0.000 & 1.000 & 0.000 & 1.000 & 0.000 \\
\hline Signing a petition & 0.804 & 0.050 & 0.826 & 0.053 & 0.812 & 0.036 \\
\hline Donating money & 0.700 & 0.052 & 0.639 & 0.046 & 0.669 & 0.034 \\
\hline Boycotting products & 1.457 & 0.070 & $1.4 \mathrm{II}$ & 0.074 & 1.437 & 0.050 \\
\hline Buycotting products & 1.569 & 0.074 & $1.53 \mathrm{I}$ & 0.082 & $\mathrm{I} .553$ & 0.054 \\
\hline Displaying message & 0.955 & 0.069 & 1.039 & 0.070 & 1.000 & 0.048 \\
\hline Contacting public officials & 0.803 & 0.083 & 0.749 & 0.073 & 0.774 & 0.055 \\
\hline Mean political participation 2008* & & & 0.102 & 0.022 & 0.096 & 0.022 \\
\hline
\end{tabular}

Notes: WLSMV estimator; * mean political participation 2006 is constrained to be 0.

Collective political participation

\begin{tabular}{llllll}
\hline Model & Chi $^{2}$ & Df & P-value & CFI & RMSEA \\
\hline Unconstrained factor loadings & 1.774 & $\mathrm{I}$ & 0.1829 & 0.997 & 0.014 \\
Constrained factor loadings & 2.078 & 3 & 0.5564 & 1.000 & 0.000 \\
Chi $^{2}$ difference test & 1.136 & 2 & 0.5667 & & \\
\hline
\end{tabular}

Notes: * Factor loading of attending a show with political content constrained at I.

Unstandardized factor loadings collective political participation

\begin{tabular}{|c|c|c|c|c|c|c|}
\hline & \multicolumn{2}{|c|}{ Unconstrained 2006} & \multicolumn{2}{|c|}{ Unconstrained 2008} & \multicolumn{2}{|c|}{ Constrained } \\
\hline & Estimate & SE & Estimate & SE & Estimate & SE \\
\hline $\begin{array}{l}\text { Attending a show with } \\
\text { political content }\end{array}$ & 1.000 & 0.000 & $\begin{array}{l}1.000 \\
0.703\end{array}$ & 0.000 & 0.541 & 0.057 \\
\hline $\begin{array}{l}\text { Participating in a legal } \\
\text { protest }\end{array}$ & 0.916 & 0.286 & 1.260 & 0.138 & 0.407 & 0.043 \\
\hline $\begin{array}{l}\text { Member of a political } \\
\text { party }\end{array}$ & 1.615 & 0.457 & & 0.246 & 0.729 & 0.077 \\
\hline $\begin{array}{l}\text { Mean political participation } \\
\text { 2008* }\end{array}$ & - & - & 0.088 & 0.070 & 0.147 & 0.123 \\
\hline
\end{tabular}

Notes: WLSMV estimator; * mean political participation 2006 is constrained to be 0.

Note: In these models we test whether the measurement equivalence of the latent concepts that were measured using multiple items (i.e. individual political participation, collective political participation, and political trust), warrants comparison between 2006 and 2008 results. 
Appendix 3. Equivalence of factor structure of political trust

Political trust

\begin{tabular}{llrlll}
\hline Model & Chi $^{2}$ & Df & P-value & CFI & RMSEA \\
\hline Unconstrained factor loadings & 2560.865 & 23 & 0.000 & 0.925 & 0.162 \\
Constrained factor loadings & 2567.782 & 28 & 0.000 & 0.924 & 0.147 \\
Chi ${ }^{2}$ difference test & 6.917 & 5 & $6.917(\mathrm{~ns})$ & & \\
\hline
\end{tabular}

Note: * Factor loading of federal parliament constrained at I.

Unstandardized factor loadings political trust

\begin{tabular}{|c|c|c|c|c|c|c|}
\hline & \multicolumn{2}{|c|}{ Unconstrained 2006} & \multicolumn{2}{|c|}{ Unconstrained 2008} & \multicolumn{2}{|c|}{ Constrained } \\
\hline & Estimate & SE & Estimate & SE & Estimate & SE \\
\hline Federal parliament & 1.000 & 0.000 & 1.000 & 0.000 & 0.932 & 0.003 \\
\hline Provincial parliament & 0.949 & 0.009 & 0.947 & 0.010 & 0.894 & 0.004 \\
\hline Police & 0.652 & 0.015 & 0.623 & 0.015 & 0.570 & 0.009 \\
\hline Government & 0.934 & 0.011 & 0.933 & 0.013 & 0.818 & 0.005 \\
\hline Political parties & 0.749 & 0.013 & 0.745 & 0.013 & 0.713 & 0.007 \\
\hline Courts & 0.729 & 0.014 & 0.682 & 0.014 & 0.652 & 0.008 \\
\hline Mean political trust $2008^{*}$ & & & -0.039 & 0.051 & -0.008 & 0.023 \\
\hline
\end{tabular}

Notes: ML estimator; * mean political participation 2006 is constrained to be 0 .

\section{Notes}

1. For methodological reasons, this automatically implies that we also test for differences in the self-selection into both kinds of participation. Although we do not have any sound theoretical reasons to expect different self-selection effects for individual and collective participation, allowing for this test is necessary in order to reach symmetric and comparable structural equation models.

2. For some acts, it can indeed be questioned whether the act should be seen as individualized or collective. Different operationalizations, however, did not lead to different results in the final analysis.

3. This test means that the full model was run again, but with constraints added to the model specification. This new model is meaningless content-wise, as the researcher specifies the relationships between the variables. The intent, however, is to obtain test statistics for these new models, and to be able to compare them to the baseline model with unconstrained cross-lagged effects. In the text, we only report on these test statistics. Full models are available from the authors.

4. Strictly speaking, and in line with the logic that we developed for the other models, we have no reason to prefer the unconstrained model over the constrained model. Given the fact that the unconstrained model conveys more information, however, we will report the unconstrained model in Table 5.

\section{References}

Ajzen I and Fishbein M (2005) The influence of attitudes on behavior. In: Albarracín D Johnson BT and Zanna MP (eds) The Handbook of Attitudes. Mahwah, NJ: Erlbaum, pp. 173-221.

Almond GA and Verba S 1963 The Civic Culture: Political Attitudes and Democracy in Five Nations. Princeton,NJ: Princeton University Press.

Barnes S and Kaase M 1979 Political Action: Mass Participation in Five Western Democracies. Beverly Hills, CA: Sage.

Brehm J and Rahn W 1997 Individual-level evidence for the causes and consequences of social capital. American Journal of Political Science 41(3): 999-1023. 
Claassen RL 2008 Testing the reciprocal effects of campaign participation. Political Behavior 30(3): 277-296.

Dalton RJ 2007 The Good Citizen: How a Younger Generation is Reshaping American Politics. Washington, DC: CQ Press.

Eder D and Nenga SK 2003 Socialization in adolescence. In: Delamater J (ed.), Handbook of Social Psychology. New York: Kluwer Academic, pp.157-182.

Finkel SE 1985 Reciprocal effects of participation and political efficacy: a panel analysis. American Journal of Political Science 29(4): 891-913.

Finkel SE 1987 The effects of participation on political efficacy and political support: evidence from a West German panel. Journal of Politics 49(2): 441-464.

Finkel SE 2007 Linear panel analysis. In: Menard S (ed.), Handbook of Longitudinal Research: Design, Measurement, and Analysis. New York: Elsevier, pp. 475-504.

Flanagan CA 2004 Volunteerism, leadership, political socialization, and civic engagement. In: Lerner R and Steinberg L (eds), Handbook of Adolescent Psychology. Hoboken, NJ: John Wiley, 721-745.

Harmon-Jones E and Harmon-Jones C 2002 Testing the action-based model of cognitive dissonance: the effect of action-orientation on post-decisional attitudes. Personality and Social Psychology Bulletin 28(6): 711-723.

Haslam AS 2001 Psychology in Organizations: The Social Identity Approach. London: Sage.

Hooghe M 2003a Participation in voluntary associations and value indicators: the effect of current and previous participation experiences. Nonprofit and Voluntary Sector Quarterly 32(1): 47-69.

Hooghe M 2003b Value congruence and convergence within voluntary associations: ethnocentrism in Belgian organizations. Political Behavior 25(2): 151-175.

Jennings MK 1987 Residues of a movement: the aging of the American protest generation. American Political Science Review 81(2): 367-382.

Kraus SJ 1995 Attitudes and the prediction of behavior: a meta-analysis of the empirical literature. Personality and Social Psychology 21(1): 58-75.

Leighley JE 1991 Participation as a stimulus of political conceptualization. Journal of Politics 53(1): 198-211.

Maloney WA 2008 Interest groups, social capital, and democratic politics. In: Castiglione D van Deth JW and Wolleb G (eds), The Handbook of Social Capital. Oxford: Oxford University Press, 303-326.

Metz EC and Youniss J 2005 Longitudinal gains in civic development through school-based required service. Political Psychology 26(3): 413-437.

Nannestad P 2008 What have we learned about generalized trust, if anything? Annual Review of Political Science 11: 413-436.

Newton K 1997 Social capital and democracy. American Behavioral Scientist 40(5): 575-586.

Olson JM and Stone J 2005 The influence of behavior on attitudes. In: Albarracín D Johnson BT and Zanna MP (eds), The Handbook of Attitudes. Mahwah, NJ: Erlbaum, pp. 223-271.

Pattie C Seyd P and Whiteley P 2003 Citizenship and civic engagement: attitudes and behavior in Britain. Political Studies 51(3): 443-468.

Paxton P 2007 Association memberships and generalized trust: a multilevel model across 31 countries. Social Forces 86(1): 47-76.

Pitts SC West SG and Tein J-Y 1996 Longitudinal measurement models in evaluation research: examining stability and change: innovative methodologies for longitudinal evaluation of human service programs. Evaluation and Program Planning 16(4): 333-350.

Prewitt K 1965 Political socialization and leadership selection. Annals of the American Academy of Political and Social Science 361: 96-111.

Putnam RD 1993 Making Democracy Work: Civic Traditions in Modern Italy. Princeton, NJ: Princeton University Press.

Putnam RD 2000 Bowling Alone: The Collapse and Revival of American Democracy. New York: Simon \& Schuster.

Quintelier E 2008 Who is politically active: the athlete, the Scouts member or the environmental activist? Young people, voluntary engagement and political participation. Acta Sociologica 51(4): 355-370. 
Sapiro V 2004 'Not your parents' political socialization: introduction for a new generation. Annual Review of Political Science 7: 1-23.

Scarrow S and Gezgor B 2010 Declining memberships, changing members? European political party members in a new era. Party Politics 16: 823-843.

Schlueter E and Davidov E 2007 Applying autoregressive aross-lagged and latent growth curve models to a three-wave panel study. In: Schmidt P van Montfort K Oud J and Satorra A (eds), Longitudinal Models in the Behavioral and Related Sciences. Mahwah, NJ: Routledge Academic, pp. 315-336.

Sigel R 1989 Political Learning in Adulthood. Chicago, IL: University of Chicago Press.

Stolle D 1998 Bowling together, bowline alone: the development of generalized trust in voluntary associations. Political Psychology 19(3): 497-525.

Uslaner EM 2002 The Moral Foundations of Trust. Cambridge: Cambridge University Press.

Valentino N Gregorowicz K and Groenendyk E 2009 Efficacy, emotions and the habit of participation. Political Behavior 31(3): 307-330.

van Deth JW and Maloney W (eds) 2011 New Participatory Dimensions in Civil Society: Professionalization and Individualized Collective Action. London: Routledge.

van Deth JW Montero JR and Westholm A (eds) 2007 Citizenship and Involvement in European Democracies: A Comparative Analysis. London: Routledge.

Verba S 1961 Small Groups and Political Behavior. Princeton, NJ: Princeton University Press.

Wollebaek D and Selle P 2003 The Importance of passive membership for social capital formation. In: Hooghe M and Stolle D (eds), Generating Social Capital. New York: Palgrave, pp. 67-88.

Youniss J 1980 Parents and Peers in Social Development. Chicago, IL: University of Chicago Press.

\section{Biographical notes}

Ellen Quintelier is a post-doctoral researcher of the Fund for Scientific Research (FWO-Vlaanderen) at the Department of Political Science of the University of Leuven (Belgium). Her main research interest is political participation among adolescents and young adults. AdDress: Department of Political Science, University of Leuven, Parkstraat 45, B-3000 Leuven, Belgium [email: Ellen. Quintelier@soc.kuleuven.be].

Marc Hooghe is a Professor of Political Science at the Department of Political Science of the University of Leuven (Belgium), and a Visiting Professor at the Universities of Lille (France) and Mannheim (Germany). He publishes mainly on political participation and social capital. ADDRESS: Department of Political Science, University of Leuven, Parkstraat 45, B-3000 Leuven, Belgium [email: Marc.Hooghe@soc.kuleuven.be]. 